\title{
LEGISLAÇÃO DO EXERCICIO DE ENFERMAGEM NO BRASIL
}

\author{
Paulina Kurcgant *
}

\begin{tabular}{l|c|}
\cline { 2 - 2 } & $\mathrm{RBEn} / 09$ \\
\hline
\end{tabular}

KURCGANT, P. - Legislaçåo do Exercicio de Enfermagem no Brasll. Rev. Bras Enf.; DF, 28 : 88-98, 1976.

\section{INTRODUÇAO}

Após quase trinta anos de luta da Associação Brasileira de Enfermagem, foi promulgada a Lei Federal n.o 5.905 , de 12 de Julho de 1973, criando os Conselhos Federal e Regionais de Enfermagem, dando aos profissionais do País instrumento adequado para a disciplinação e a fiscalização do exercício da enfermagem no Brasil.

Este fato constituiu uma das maiores conquistas da enfermagem brasileira nestes últimos anos. A exemplo dos profissionais de outras áreas, as enfermeiras desejavam ter o controle de sua própria profissão, especialmente no campo da fiscalização das atividades próprias e de todo o pessoal auxiliar que trabalha sob sua orientação e supervisão. Desejavam poder participar, com autoridade, das resoluções que pudessem afetar de algum modo sua atuação na equipe de saúde.

Até a criação dos Conselhos, os profissionais de enfermagem contavam apenas com entidades de classe de caráter cientifico-cultural e órgãos de defesa dos interesses de classe.

Entre as primeiras estão: Associação Brasileira de Obstetriz e a União Nacional dos Auxiliares de Enfermagem. Do segundo grupo constam dois sindicatos: o de Parteiras e o de "Profissionais de Enfermagem, Técnicos, Duchistas, Massagistas e Empregados em Hospitais e Casa de Saúde".

As enfermeiras ainda não possuem o seu sindicato; estão sendo criadas Associações Profisisonais de Enfermagem, que é a primeira fase no processo de organização de sindicatos.

A Associação Brasileira de Enfermagem, sociedade civil de direito privativo, de caráter cultural e assistencial, congrega as enfermeiras do País. Recentemente ampliou sua finalidade, estendendo a possibilidade de fillação às obstetrizes ou enfermeiras obstétricas e aos técnicos de enfermagem. Fol, até o presente, a entidade polivalente, que a par das atividades próprias, para o incentivo do espírito de união e cordialidade entre os membros da classe e para o

- Professor colaborador da Escola de Enfermagem da USP. 
KURCGANT, P. - Legislaçăo do Exercíclo de Enfermagem no Brasil. Ret. Bras. Enf;; DF, $28: 88-98,1976$.

aperfeiçoamento técnico-cultural dos profissionais, tem exercido a função de defesa da classe; sua voz tem sido ouvida pelas autoridades governamentais, especialmente em relação aos problemas do ensino da enfermagem.

\section{OS CONSELHOS DE ENFERMAGEM}

As Ordens, Conselhos ou Colégios, órgãos oficiais de seleção, disciplinam e fiscalizam o exercício profissional de uma classe e constituem entidades institucionais cuja importância deve ser salientada, posto que substituem o Estado no exercício de determinadas funçōes, tais como: cadastramento das pessoas que podem exercer uma determilnada profissão, de acordo com a legislação vigente; avaliação de seus títulos e registro na categoria a que pertence; combate ao exercício llegal da profissão: verificação do cumprimento estrito das normas contidas no Código de Deontologia Profissional; punição aos infratores desse Código, e promoção de estudos e campanhas visando ao aperfeiçoamento dos membros da classe.

A função e competência de fiscalizar as atividades profissionais é justificada pela natureza de direito público do Conselho. Essa função não tíra, dos profissionais, a liberdade de exercerem e desenvolverem suas atividades, restringindo apenas aquelas que se contrapōem à liberdade dos demais.

O Conselho não é uma entidade de ingresso facultativo, todos os profissionais são obrigados a se registrarem no Conselho; não o fazendo, ficam proibidos de exercer qualquer atividade remunerada em sua profissão.

Numa retrospectiva, podemos avaliar a luta de outros profissionais pela criação de seu Conselho ou Ordem, não só no Brasil, como em outros países.

A classe dos advogados, estimulada pela própria formação profissional, an- tecipou-se às demais nessa conquista e hoje já estão numa nova fase, trabalhando para ganhar plena autonomia, desvinculando-se do Ministério do Trabalho.

Antes de analisar o conteúdo da Lei n. ${ }^{\circ}$ 5.905/73, que criou os Conselhos de Enfermagem no Brasil, convém retroceder no tempo e focalizar aspectos do desenvolvimento da enfermagem e da obstetrícia no País.

O primeiro curso de obstetrícia foi criado por uma lei de 1832, que oficializou esse ensino entre nós. Documentos legais subseqüentes modificaram o currículo inicial do curso e regularam o exercício da enfermeira obstétrica ou parteira, conjuntamente com os demais profissionais da área da saúde.

A primeira escola de enfermagem foi criada em 1890, entretanto, somente em 1923 fol criada uma escola realmente de nível equivalente às congêneres dos outros países. Em 1931 o exercício da enfermagem foi regulado por uma lel que apenas determinava quem poderia usar o título de enfermeira diplomada, e a obrigatoriedade do registro do diploma do Departamento Nacional de Saúde Pública.

Até 1955, as duas profissōes de enfermagem e obstetrícia, tínham legislação de exercício distintas. A Lei n. ${ }^{\circ}$.604/55, que "regula o exercício da enfermagem profissional" e o Decreto n.o 50.387/61. que a regulamentou, englobaram todos os que exerciam atividades de enfermagem, classificando-os em categorias distintas que incluíam as enfermeiras, as obstetrizes ou enfermeiras obstétricas e todo o pessoal auxiliar, menos os atendentes. Estes não têm seu exercício regulado em lei.

Entretanto, a legislação do ensino de obstetrícia continuou separada da de enfermagem ainda por algum tempo, até que fol determinado o Currículo Mínimo 
KURCGANT, P. - Legislaçāo do Exercício de Enfermagem no Brasil. Rev. Bras. Enf.; DF, 28 : 88-98, 1976.

dos Cursos de Enfermagem e Obstetricia, em 1972, juntando, definitivamente os dois cursos.*

As lutas por uma lei criando o Conselho de Enfermagem tiveram inicio em 1947, quando a Associação Brasileira de Enfermagem, obedecendo a uma das recomendaçōes do $1 .^{\circ}$ Congresso Brasileiro de Enfermagem, encaminhou ao Ministro da Educação e Saúde um anteprojeto nesse sentido, solicitando um órgão normativo, de orientação, consulta e coordenação, incluindo não só aspectos do exercício mas também com o ensino de enfermagem.

Em 1961, a comissão criada para estudar o assunto apresentou um anteprojeto da criação do Conselho como órgão normativo do exercício dos profissionais de enfermagem no País, não fazendo referência ao ensino. Como "profissionais de enfermagem", de acordo com a lei de exercício, o Conselho deveria abranger enfermeiras, obstetrizes, auxilares de enfermagem, parteiras, enfermeiros práticos, práticos de enfermagem e parteiras práticas. Esse anteprojeto deu motivo a uma forte reação por parte das obstetrizes que reivindicaram Conselho próprio, resultando em mais uma tentativa falha.

Em 1964, novo anteprojeto foi elaborado incluindo somente as enfermeiras. Porém, o Conselho Nacional de Saúde acrescentou novamente as obstetrizes. O processo teve tramitação muito demorada, sofrendo, no seu curso, diversas modificações. Finalmente, pela Lei n. ${ }^{\circ} 5.905$, de $12 / 7 / 1973$ foram criados os Conselhos Federal e Regionais de Enfernagem, (anexo I) que constituem, em seu conjunto, uma autarquia vinculada ao Ministério do Trabalho; são "órgãos disciplinadores do exercício da enfermagem, incluindo todas as categorias pro- fissionais compreendidas nos serviços de enfermagem".

\section{CARACTERISTICAS DOS CONSELHOS DE ENFERMAGEM}

O Conselho Federal de Enfermagem tem jurisdição em todo o território nacional e sede no Distrito Federal; é constituído de nove membros efetivos e igual número de suplentes, portadores de diploma de curso de enfermagem de nível superior. A ele estão subordinados os Conselhos Regionais; cabe-lhe, entre outras perrogativas, cassar o direito de exercer a enfermagem daqueles profissionais que, por terem infringido determinações do Código de Deontologia, estejam sujeitos a essa penalidade máxima.

Os Conselhos Regionais são instalados, cada um em um dos Estados ou Territórios da Federação, quando o número de profissionais for suficiente (minimo de 50). Podem ter até 21 membros na proporção de três quintos de enfermeiros e dois quintos de profissionais das demais classes de pessoal de enfermagem, reguladas em Lei. Esta composição não agradou os enfermeiros, mas a Associação Brasileira de Enfermagem foi vencida em esforços para que o Conselho fosse constituído apenas de pessoal de nivel universitário.

Como os Conselhos são responsáveis pela fiscalização do exercício profissional de todos os que trabalham em serviços de enfermagem, foram criados três Quadros distintos, de acordo com as categorias profissionais existentes:

Quadro I: enfermeiros e obstetrizes ou enfermeiras obstétricas

Quadro II: técnicos de enfermagem

Quadro III: auxiliares de enfermagem,

* De acordo com a nova legislaçāo de ensino de enfermagem, as obstetrizes ou enfermeiras obstétricas fazem o curso de enfermagem geral antes de se habilitarem em enfermagem obstétrica. 
KURCGANT, P. - Legislaçāo do Exercício de Enfermagem no Brasil. Rev. Bras. Ent.; DF, $28: 88-98,1976$.

práticas de enfermagem e parteiras práticas.

$O$ atendente de enfermagem embora constitua uma grande parte dos recursos humanos de enfermagem no País, não tem nenhuma formaçāo profissional e não é abrangido pelo Conselho Federal de Enfermagem.

Para o desempenho de sua função disciplinar e normativa o Conselho Federal de Enfermagem elaborou o Código de Deontologia de Enfermagem (anexo II) estabelecendo os padrōes de conduta para os profissionais no exercício de suas atividades. Esses padrōes são imprescindíveis para o aprimoramento da assistência de enfermagem no País.

A criação do Conselho Federal de Enfermagem não implicará no desaparecimento da Associação Brasileira de Enfermagem (ABEn). Como acontece com as demais profissōes no Brasil, a enfermagem terá os 3 (três) tipos de entidades de classe, cada um com seus objetivos específicos.

A ABEn continuará uma sociedade civil, de direito privado, de caráter cul- tural e assistencial, de filliação facultativa. O sindicato, em vias de criação, órgão oficial de defesa da classe, terá como finalidade o "estudo, coordenação e defesa dos seus interesses econômicos ou profissionais".

Ao assumirem a responsabilidade pela disciplina e físcalização do exercício de sua profissāo, por meio dos Conselhos Federal e Regionais de Enfermagem, as enfermeiras brasileiras demonstraram ter atingido, de fato, a maturidade que o status de profissional de nível universitário já lhes conferia, de direito.

Maria Rosa Pinheiro, líder inconteste da enfermagem no Brasil, pondera, muito judiciosamente:

"Têm agora os profissionais de enfermagem a oportunidade de disciplinar e fiscalizar a própria profissão. Terão eles, igualmente, armas para coibir os generalizados abusos de serviçcs de saúde que se utilizam de mãode-obra não qualificada, concedendolhe o título privativo dos profissionais regulados em lei? Eis a grande pergunta que o futuro responderá".

\section{BIBLIOGRAFIA}

1. CAMARGO, M. - Etica, Vida e Saúde - Etica Profssional para cursos na área de saúde. Petrópolis. Vozes, 1976.

2. CONSELHO NACIONAL DE ENFERMAGEM - Editorial. Anais de Enfermagem. 1 (3) : 105-106, jun., 1948.

3. JORGE, D.R. - Evoluçāo da Legislação Federal do Ensino e do exercício Profissicnal da Obstetriz (Parteira) no Brasil; Tese para o concurso de Docente Livre na Es- cola de Enfermagem Ana Neri da Universidade Ferleral do Rio de Janeiro. São Pauln. Escola de Enfermagem da USP, 1975.

4. OLIVEIRA, J.G. - História dos órgãos de classe dos advogados. Sāo Paulo. Bentivegna. 1968.

5. PINHEIRO, M.R.S. - Editorial: Conselhos Federal e Regionais de Enfermagem. Revista da Escola de Enfermagem da USP. 9 (2) : 257258, ago., 1975. 


\title{
ANEXO I \\ CONSELHO FEDERAL DE ENFERMAGEM
}

\author{
LEIS
}

\section{N. ${ }^{\circ}$ 5.905, de 12 de jultho de 1973}

- Dispõe sobre a criação dos Conselhos Federal e Regionais de Enfermagem e dá outras providências.

\section{O Presidente da República}

Faço saber que o Congresso Nacional decreta e eu sanciono a seguinte Lei:

Art. 1.'. São criados o Conselho Federal de Enfermagem (COFEN) e os Conse'hos Regionais de Enfermagem (COREN), constituindo em seu conjunto uma autarquia, vinculada ao Ministério do Trabalho e Previdência Social.

Art. 2. . O Conselho Federal e os Conselhos Regionais são órgãos disciplinadores do exercício da profissão de enfermeiro e das demais profissōes compreendidas nos serviços de enfermagem.

Art. 3.0. O Conselho Federal, ao qual ficam subordinados os Conselhos Regionais, terá jurisdiçāo em todo o território nac'onal e sede na Capital da República.

Art. 4. ${ }^{\circ}$ Haverá um Conselho Regional em cada Estado e Território, com sede na respectiva capital, e no Distrito Federal.

Parágrafo único. O Conselho Federal poderá, quando o número de profissionais habilitados na unidade da federação for inferior a cinqüenta, determinar a formação de regiōes, compreendendo mais de uma unidade.

Art. 5. ${ }^{\circ}$ O Conselho Federal terá nove membros efetivos e igual número de suplentes, de nacionalidade brasileira, e portadores de diploma de curso de Enfermagem de nível superior.

Art. 6. ${ }^{\circ}$. Os membros do Conselhos Federal e respectivos suplentes serão eleitos por maioria de votos, em escru- tínio secreto, na Assembléia dos Delegados Regionais.

Art. 7. ${ }^{\circ}$ O Conselho Federal elegerá dentre seus membros, em sua primeira reuniāo, o Presidente, o Vice-Presidente, o Primeiro e o Segundo Secretários e o Primeiro e o Segundo Tesoureiros.

Art. 8. . Compete ao Conselho Federal:

I - aprovar seu regimento interno e os dos Conselhos Regionais;

II - instalar os Conselhos Regionais; III - elaborar o Código de Deontolcgia de Enfermagem e alterá-lo, quando necessário, ouvidos os Conselhos Regionais;

IV - baixar provimentos e expedir instruçōes, para uniformidade de procedimento e bom funcionamento dos Conselhos Regionais;

V - dirimir as dúvidas suscitadas pelos Conselhos Regionais;

VI - apreciar, em grau de recursos, as decisōes dos Conselhos Regionais;

VII - instituir o modelo das carteiras profissionais de identidade $e$ as insígnias da profissão;

VIII - homologar, suprir ou anular atos dos Conselhos Regionais;

IX - aprovar anualmente as contas e a proposta orçamentária da autarquia, remetendo-as aos órgãos competentes;

$\mathrm{X}$ - promover estudos e campanhas para aperfeiçoamento profissional;

$\mathrm{XI}$ - publicar relatórios anuais de seus trabalhos;

XII - convocar e realizar as eleições para sua diretoria; 
KURCGANT, P. - Legislaçåo do Exercício de Enfermagem no Brasill. Rev. Bras, Ene: DF, 28 : 88-98, 1976.

XIII - exercer as demais atribuições que lhe forem conferidas por lei.

Art. 9.0. O mandato dos membros do Conselho Federal será honorifico e terá a duração de três anos, admitida uma reeleição.

Art. 10. A receita do Conselho Federal de Enfermagem será constituída de:

I - um quarto da taxa de expedição das carteiras profissionais;

II - um quarto das multas aplicadas pelos Conselhos Regionais;

III - um quarto das anuidades recebidas pelos Conselhos Regionais;

IV - doações e legados;

V - subvençōes oficiais;

VI - rendas eventuais.

Parágrafo único. Na organização dos quadros distintos para inscrição de profissionais o Conselho Federal de Enfermagem adotará como critério, no que couber, o disposto na Lel n.o 2.604, de 17 de setembro de 1955.

Art. 11. Os Conselhos Regionais serão instalados em suas respectivas sedes, com cinco a vinte e um membros e outros tantos suplentes, todos de nacionalidade brasileira, na proporção de três quintos de enfermeiros e dois quintos de profissionais das demais categorias do pessoal de enfermagem reguladas em lei.

Parágrafo único. O número de membros dos Conselhos Regionais será sempre ímpar, e a sua fixação será feita pelo Conselho Federal, em proporção ao número de profissionais inscritos.

Art. 12. Os membros dos Conselhos Regionais e respectivos suplentes serão eleitos por voto pessoal, secreto e obrigatório, em época determinada pelo Conselho Federal, em Assembléia Geral especialmente convocada para esse fim.

8 1.o. Para a eleição referida neste artigo serão organizadas chapas separa- das, uma para enfermeiros e outra para os demais profissionais de enfermagem. podendo votar, em cada chapa, respectivamente, os profissionais referidos no artigo 11.

8 2.0. Ao eleitor que, sem causa justa, deixar de votar nas eleiçōes referidas neste artigo, será aplicada pelo Conselho Regional multa em importância correspondente ao valor da anuidade.

Art. 13. Cada Conselho Regional elegerá seu Presidente, Secretárío e Tesoureiro, admitida a criação de cargos de Vice-Presidente, Segundo Secretário e Segundo Tesoureiro, para os Conselhos com mais de doze membros.

Art. 14. O mandato dos membros dos Conselhos Regionals será honorífico e terá duração de três anos, admitida uma reeleição.

Art. 15. Compete aos Conselhos Regionais:

I - deliberar sobre Inscrição no Conselho e seu cancelamento;

II - disciplinar e fiscalizar o exercicio profissional, observadas as diretrizes gerais do Conselho Federal;

III - fazer executar as instruçōes e provimentos do Conselho Federal;

IV - manter o registro dos profissionais com exercício na respectiva jurisdição;

v - conhecer e decidir os assuntos atinentes à ética profissional, impondo as penalidades cabiveis;

VI - elaborar a sua proposta orçamentária anual e o projeto de seu regimento interno e submetê-los à aprovação do Conselho Federal;

VII - expedir a carteira profissional indispensável ao exercício da profissão, a qual terá fé pública em todo o território nacional e servirá de documento de identidade; 
KURCGANT, P. - Legislaçāo do Exercício de Enfermagem no Brasil. Rev. Bras. Enf.; DF, $28: 88-98,1976$.

VIII - zelar pelo bom conceito da profissão e dos que a exerçam;

IX - publicar relatórios anuais de seus trabalhos e a relação dos profissionais registrados;

$\mathbf{X}$ - propor ao Conselho Federal medidas visando à melhoria do exercício profissional;

XI - fixar o valor da anuidade;

XII - apresentar sua prestação de contas ao Conselho Federal, até o dia 28 de fevereiro de cada ano;

XIII - eleger sua diretoria e seus delegados eleitores ao Conselho Federal;

XIV - exercer as demais atribuições que lhes forem conferidas por esta Lei ou pelo Conselho Federal.

Art. 16. A renda dos Conselhos Regionais será constituída de:

I - três quartos da taxa de expedição das carteiras profissionais;

II - três quartos das multas aplicadas;

III - três quartos das anuidades;

IV - doações e legados;

V. - subvenções oficiais, de empresas ou entidades particulares;

VI - rendas eventuais.

Art. 17. O Conselho Federal e os Conselhos Regionais deverão reunir-se, pelo menos, uma vez mensalmente.

Parágrafo único. O Conselheiro que faltar, durante o ano, sem licença prévia do respectivo Conselho, a cinco reuniōes perderá o mandato.

Art. 18. Aos infratores do Código de Deontologia de Enfermagem poderão ser aplicadas as seguintes penas:

I - advertência verbal;

II - multa;

III - censura;

IV - suspensão do exercício profissional;

V - cassação do direito ao exercício profissional.

$\S 10^{\circ}$. As penas referidas nos incisos I, II, III e IV deste artigo são da alçada dos Conselhos Regionais e a referida no inciso V, do Conselho Federal, ouvido o Conselho Regional interessado.

\& 2.0. O valor das multas, bem como as infraçōes que implicam nas diferentes penalidades, serão disciplinados no Regimento do Conselho Federal e dos Conselhos Regionais.

Art. 19. O Conselho Federal e os Conselhos Regionais terão tabela própria de pessoal, cujo regime será o da Consolidação das Leis do Trabalho.

Art. 20. A responsabilidade pela gestão administrativa financeira dos Conselhos caberá aos respectivos diretores.

Art. 21. A composição do primeiro Conselho Federal de Enfermagem, com mandato de um ano, será feita por ato do Ministro do Trabalho e Previdência Social mediante indicação, em lista tríplice, da Associação Brasileira de Enfermagem.

Parágrafo único. Ao Conselho Federal assim constituído caberá além das atribuições previstas nesta Lei:

a) promover as primeiras eleições para composição dos Conselhos Regionais e instalá-los;

b) promover as primeiras eleições para composição do Conselho Federal, até noventa dias antes do término do seu mandato.

Art. 22. Durante o período de organização do Conselho Federal de Enfermagem, o Ministério do Trabalho e Previdência Social the facilitará a utilização de seu próprio pessoal, material e local de trabalho.

Art. 23. Esta Lei entrará em vigor na data de sua publicação, revogadas as disposiçōes em contrário.

Brasília, 12 de julho de 1973

(Ass.) Emílio G. Médici, Presidente da República e Júlio Barata, Ministro do Trabalho e Previdência Social. 


\section{ANEXO II \\ CONSELHO FEDERAL DE ENFERMAGEM CÓDIGO DE DEONTOLOGIA DE ENFERMAGEM Aprovado pela Resolução COFEN-9, de 4/10/1975}

O presente Código de Deontologia de Enfermagem fundamenta-se nos princípios postulados pela Declaração Universal dos Direitos do Homem, adotada e promulgada pela Assembléia Geral das Nações Unidas, em 1948, e pela Convenção de Genebra da Cruz Vermelha, de 1949, e contidos nos Códigos de tica do Conselho Internacional de Enfermeiras (ICN), do Comitê Internacional Católico de Enfermeiras e Assistentes Médico-Sociais (CICIAMS) e da Associação Brasileira de Enfermagem (ABEN).

\section{Capitulo I}

Das responsabilidades fundamentais

Art. 1.0 A responsabilidade fundamental do enfermeiro é prestar assistência de enfermagem ao indivíduo, à família e à comunidade, em situaçōes que requerem medidas relacionadas com a promoção, proteção e recuperação da saúde, prevenção de doenças, reabilitação de incapacitados, alívio do sofrimento e promoção de ambiente terapêutico, levando em consideração o diagnóstico e o plano de tratamento médico e de enfermagem.

Art. 2.0 São deveres do enfermeiro: I - exercer sua atividade com zelo, probidade e compreensão da própria responsabilidade, obedecendo aos preceitos da moral, da ética profissional e das leis vigentes no País;

II - diagnosticar as necessidades de enfermagem dos clientes, a fim de elaborar o plano de cuidados correspondente;
III - prestar assistência de enfermagem aos indivíduos dela necessitados, respeitando a dignidade e os direitos da pessoa humana, independentemente de quaisquer considerações relativas a etnia, nacionalidade, credo político, religiāo, sexo e condição sócio-econômica; a prioridade no atendimento deve obedecer exclusivamente a razōes de urgência do caso;

IV - respeitar a vida humana desde a concepção até a morte, jamais cooperando em atos em que voluntariamente se atente contra a vida, ou que visem a destrułção da integridade física ou psíquica do ser humano;

V - respeitar os valores culturais e as crenças religiosas de seus pacientes e zelar para que não lhes falte assistência espiritual;

VI - colocar seus serviços profissionais à disposição da comunidade em caso de guerra, catástrofe ou de graves crises sociais, independentemente de qualquer proveito pessoal;

VII - executar as prescrições médicas, exceto quando contrárias à moral ou à ética profissional, ou à segurança do cliente;

VIII - proteger o paciente contra eventuais falhas, imprudências, negligências, omissões ou impericia em relação ao seu atendimento, por parte de qualquer dos membros da equipe de saúde. Constatado um fato dessa natureza, discutir o assunto com o profissional faltoso e, em última instância, recorrer à chefia a fim de que sejam tomadas medidas para salvaguardar a segurança e o conforto do paciente; 
EURCGANT, P. - Legislaçăo do Exercício de Enfermagem no Brasill. Rev. Bras, En?.; DF, $28: 88-98,1976$.

IX - respeitar o natural pudor e intimidade do paciente;

$\mathrm{X}$ - respeitar o direito do paciente de decidir sobre sua pessoa e seu bemestar.

Art. 3.

I - negar assistência de enfermagem, em caso de urgência, sem que haja outro profissional para garanti-la;

II - abandonar o paciente em meio a um tratamento sem causa justa e sem a garantia de continuidade de assistência;

III - prescrever medicamentos a não ser em casos de extrema urgência e nos previstos na legislaçāo vigente;

IV - administrar terapêutica e colaborar em intervençōes cirúrgicas e tratamentos desnecessários ou proibidos pela moral ou pela legislação vigente, ou praticados sem o consentimento do paciente, ou de seu representante legal, se se tratar de menor ou incapaz;

V - praticar o aborto ou colaborar em práticas destinadas a provocá-lo;

VI - praticar a eutanásia ou colaborar em práticas destinadas a antecipar a morte do paciente;

VII - realizar ou participar de pesquisas em que os direitos inalienáveis do homem sejam desrespeitados, que acarretem perigo de vida ou dano à sua saúde física ou mental, ou que envolvam menores ou incapazes, sem o consentimento do responsável legal;

VIII - emprestar o seu nome para propaganda de drogas, tratamentos, instrumental e equipamentos hospitalares, ou de instituiçōes comerciais com atuação nesses ramos;

IX - permitir que o seu nome conste da quadro de pessoal de hospitais, casas de saúde, ambulatórios, escolas, cursos e outros estabelecimentos, sem neles exercer as funçōes de enfermagem correspondentes;

$\mathrm{X}$ - receber comissōes, vantagens ou remuneração de laboratório, entidades de assistência à saúde ou de outros esta- belecimentos comerciais que não correspondam a serviços efetivamente prestados;

XI - prestar serviços gratuitos ou a preços ífimos, salvo em benefício de pessoas reconhecidamente carentes de recursos ou a instituiçōes filantrópicas sem condiçōes de remunerá-lo adequadamente.

\section{Capítulo II}

\section{Do exercício profissional}

Art. 4. $O$ enfermeiro assume responsabilidade quanto à provisão de cuidados de enfermagem e à manutenção de elevados padrōes de competência profissional.

Art. 5. 0 enfermeiro programa e coordena todas as atividades que visam o bem-estar do paciente.

Art. 6.' O enfermeiro, como chefe de sua equipe, é responsável pelo aperfeiçoamento técnico e cultural do pessoal sob sua orientação e supervisão.

Art. 7.0 $O$ enfermeiro, no interesse de seus pacientes e de sua profissão, reprova atos dos que infringem postulados éticos ou disposiçōes legais. Ao notar inobservância de normas éticas ou da legislação em vigor, deve discuti-la com o faltoso e, se necessário, levar o assunto ao conhecimento do Conselho Regional de Enfermagem de sua jurisdição.

Art. 8. 0 onfermeiro tem 0 dever moral de notificar, por escrito, irregularidades de que tome conhecimento em função do exercício de suas atividades profissionais; em se tratando de intervençōes ou tratamentos llícitos; a notificação deverá ser encaminhada à Chefia Médica por intermédio do Serviço de Enfermagem da Instituição.

Art. 9.0 $O$ enfermeiro exerce Julgamento ético com respeito à sua competência em aceitar atribuiçōes delegadas e assume a responsabilidade somente 
EURCGANT, P. - Legislaçāo do Exercício de Enfermagem no Brasil. Rev. Bras. En?.; DF, $28: 88-98,1976$.

por tarefas para as quais esteja capacitado.

Art. 10. O enfermeiro não delega injustificadamente suas atribuiçōes a outrem.

Art. 11. O enfermeiro não permite que outro profissional assine trabalho por ele executado.

Art. 12. No interesse de seus pacientes e da instıtuição onde trabalha, 0 enfermeiro deve:

I - manter segredo sobre fatos sigiliosos de que tenha conhecimento por ter visto, ouvido ou deduzido, no exercício de suas atividades profissionais e exigir a mesma discrição do pessoal sob sua supervisão;

II - manter o prontuário do paciente fora do alcance de estranhos à equipe de saúde da instituição;

III - manter em segurança os entorpecentes e psicotrópicos quando sob sua guarda e responsabilidade.

Art. 13. No exercício de suas funçōes, o enfermeiro abster-se-á de:

I - trabalhar em entidades onde não haja respeito pelos princípios éticos estabelecidos e condições de trabalho que assegurem aos pacientes uma assistência de enfermagem adequada, ou colaborar com essas entidades;

II - administrar medicamentos sem nome ou fórmula, identificados por números ou códigos, sem certificar-se antes da natureza das drogas que os compōem.

\section{Capitulo III}

\section{Do enfermeiro e sua profissão}

Art. 14. O enfermeiro preserva a honra, o prestígio e as tradiçōes de sua profissão e as normas éticas da sociedade.

Art. 15. vedado ao enfermeiro acumpliciar-se, por qualquer forma, com pessoa que exerça ilegalmente a profissão.
Art. 16. dever do enfermeiro:

I - pertencer, no mínimo, a uma entidade da classe, da jurisdição onde exerça suas atividades profissionais;

II - apoiar as iniciativas que visem o desenvolvimento cultural e a defesa dos interesses da classe;

III - comunicar ao Conselho Regional de Enfermagem, no qual esteja inscrito, demissão de cargo, função ou emprego, motivado pela necessidade de preservar os interesses da profissão;

IV - atualizar e ampliar seus conhecimentos técnicos, científicos e culturais em benefício dos clientes a quem assiste e do desenvolvimento da profissão;

V - assumir seu papel na determinação de padrōes desejáveis do exercício e do ensino de enfermagem.

\section{Capitulo IV}

Do relacionamento com colegas e demais membros da equipe de saúde

Art. 17. O enfermeiro mantém relações de respeito e cortesia com colegas e outros profissionais e cumpre com lealdade sua parte no trabalho conjunto.

Art. 18. O enfermeiro coopera com todos os profissionais da equipe de saúde e participa dos planos que visam a provisão de serviços de assistência à comunidade.

Art. 19. O enfermeiro abster-se-á de:

I - prestar aos pacientes serviços que, por sua natureza, compete a outro profissional, salvo em caso urgente ou de calamidade pública;

II - ser conivente, mesmo a título de solidariedade, com erros, contravenção penal, ou atos praticados por colegas que infrinjam os postulados éticos que regem o exercicio profissional;

III - praticar atos de concorrência desleal aos colegas; procurar conseguir para si emprego, cargo ou função que esteja sendo exercida por colega; 
KURCGANT, P. - Legislaçāo do Exercícico de Enfermagem no Brasil. Rev. Brad. Ene.; DF, $28: 88-98,1976$.

IV - aceitar emprego deixado por colega que tenha sido dispensado sem justa causa ou que haja pedido demissão a fim de preservar a dignidade ou os interesses da profissão, salvo anuência do Conselho Regional de Enfermagem no qual esteja inscrito;

$\mathrm{V}$ - fomular criticas depreciativas a colegas e outros membros da equipe de saúde, à instituição onde trabalha e às instituiçōes de assistência à saúde.

\section{Capítulo V}

Da observância do Código

Art. 20. O enfermeiro cumpre os preceitos deontológicos contidos neste Código e leva ao conhecimento do Conselho Regional de Enfermagem competente fatos que constituem infração às suas disposiçōes.

Art. 21. Aos infratores do Código de Deontologia de Enfermagem serāo aplicadas as penas previstas no artigo 18 da Lei n. ${ }^{\circ} 5.905 / 73$.

Art. 22. As dúvidas que venham a surgir na aplicação deste Código e os casos omissos serão esclarecidos pelo Conselho Federal de Enfermagem.

Art. 23. O Conselho Federal de Enfermagem poderá alterar este Código por iniciativa própria ou mediante representação dos Conselhos Regionais: obedecidas normas regimentais.

\section{Capitulo VI}

Das disposiçōes gerais

Art. 24. O enfermeiro assume a responsabilidade civil e penal por danos causados aos clientes sob seus cuidados, por imperícia, omissão de assistência ou negligência .

Art. 25. O enfermeiro responde pessoal e judicialmente pela propriedade ou impropriedade dos próprios atos; o trabalho coletivo ou em equipe não diminui essa responsabilidade.

Art. 26. O enfermeiro tem direito a justa remuneração pelo seu trabalho e aceita como retribuição de seus serviços profisisonais somente as prestaçōes que lhe forem devidas por contrato ou pelo cargo ou função que preencha.

Art. 27. O enfermeiro, por meio de sua atuação nos órgãos de classe, participa na determinaçāo e manutençāo de condições justas de trabalho para toda a equipe de enfermagem.

Art. 28. O enfermeiro cumpre com fidelidade seus deveres cívicos e colabora com os demais profissionais e cidadãos nos programas e pesquisas que se destinam a atender às necessidades de saúde da população, em âmbito nacional e internacional.

Art. 29. As disposições contidas neste Código aplicam-se, no que couber, aos outros profissionais de enfermagem. 